\title{
Pathways between food insecurity and glycaemic control in individuals with type 2 diabetes
}

\author{
Rebekah J Walker ${ }^{1,2}$, Joni Strom Williams ${ }^{1,2}$ and Leonard E Egede ${ }^{1,2, *}$ \\ 'Department of Medicine, Division of General Internal Medicine, Medical College of Wisconsin, Milwaukee, WI, \\ USA: ${ }^{2}$ Center for Advancing Population Science, Medical College of Wisconsin, 8701 Watertown Plank Road, \\ Milwaukee, WI 53226, USA
}

Submitted 24 January 2018: Final revision received 15 May 2018: Accepted 20 June 2018: First published online 08 August 2018

\begin{abstract}
Objective: Food insecurity is reported in approximately $28 \%$ of individuals with diabetes in the USA and is associated with poor glycaemic and lipid control. The present study aimed to understand the direct and indirect pathways through which food insecurity impacts glycaemic control in individuals with diabetes.

Design/Setting/Subjects: Adults ( $n$ 615) with type 2 diabetes completed validated questionnaires after recruitment from two primary care clinics. Structural equation modelling was used to investigate mechanisms through which food insecurity influences diabetes self-care behaviours and glycaemic control, including investigation into possible direct and indirect effects of perceived stress and social support. Results: The final model showed that higher food insecurity was directly significantly related to increased stress $(r=0.14, P<0.001)$ and increased glycosylated $\mathrm{Hb}(r=0.66, P=0.03)$. Higher stress was significantly related to poorer self-care $(r=-0.54, P<0.001)$ and lower social support $(r=-0.41$, $P<0.001)$. There was no significant direct association between food insecurity and self-care, or between perceived stress and glycaemic control.

Conclusions: Food insecurity had both a direct effect on glycaemic control and an indirect effect on self-care through stress. The indirect pathway suggests that efforts to address stress may influence the ability of individuals to perform diabetes self-care behaviours. The direct effect on glycaemic control suggests that pathways independent of self-care behaviours may also be necessary to improve diabetes outcomes. Results from the study suggest a multipronged approach is necessary to address food insecurity in individuals with diabetes.
\end{abstract}

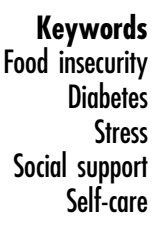

Diabetes affects over $9 \%$ of the US population, is the seventh leading cause of death, and is associated with significant morbidity, mortality, decreased quality of life, and increased health-care utilization and costs ${ }^{(1)}$. Individuals diagnosed with diabetes have average medical expenditures that are approximately 2.3 times higher than those of individuals not diagnosed with diabetes ${ }^{(1)}$. Additionally, the risk for death among people with diabetes is about twice that of similarly aged people without diabetes $^{(1)}$. Despite significant research into lifestyle interventions focused on improving glycaemic control and diabetes outcomes, national estimates suggest nearly half of those diagnosed with diabetes do not meet targets for glycaemic control and only 14\% meet combined targets for glycaemic control, blood pressure and lipids ${ }^{(2)}$.

Significant evidence supports a relationship between food security, mental and physical health, and an individual's ability to manage diabetes ${ }^{(3)}$. Food insecurity is defined by the US Department of Agriculture as an inability to or limitation in accessing nutritionally adequate foods, or dependence on emergency food supplies ${ }^{(4)}$. The overall age-standardized rate of food insecurity in the US population increased from $9 \cdot 1 \%$ in 2005 to $18.3 \%$ in 2012 , and has been shown to be particularly prevalent for those with cardiometabolic diseases ${ }^{(5)}$. For example, foodinsecure adults are two to three times more likely to have diabetes than those who are food secure, after adjustment for income, employment and lifestyle ${ }^{(3,6)}$.

One hypothesized mechanism to explain the impact of food insecurity on those with diabetes is the change in dietary intake ${ }^{(7-10)}$. Overall, reliance on lower-quality, energy-dense foods increases due to the higher cost of healthy alternatives ${ }^{(3,11)}$. However, it has also been hypothesized that food insecurity impacts an individual's ability to make decisions regarding self-management of the disease $^{(8,12)}$. For example, those with diabetes have noted that 
diabetes-specific diet behaviours such as counting carbohydrates and tracking servings were unrealistic, and meal planning became difficult with inconsistent income ${ }^{(13)}$. Selfcare behaviours, particularly medication adherence, general diet and blood sugar testing, have been shown to be associated with food insecurity ${ }^{(14)}$, but did not mediate the relationship with worse glycaemic control ${ }^{(15)}$. Food insecurity also has implications on a patient's emotional and mental health, with food-insecure patients with diabetes reporting lower overall health status, lower satisfaction with life, and higher prevalence of depression, diabetes distress and self-perceived stress ${ }^{(3,10,12,16,17)}$. Low socio-economic status has also been hypothesized to make developing and replenishing health-promoting resources more difficult, decreasing the ability to manage stress ${ }^{(18,19)}$.

Little work has been conducted investigating mediators of the relationship between food insecurity and glycaemic control, and no study to our knowledge has investigated the direct and indirect influences of factors related to diet, psychological stress and health-promoting resources such as social support. Therefore, the present study aimed to understand the direct and indirect pathways through which food insecurity impacts glycaemic control in individuals with diabetes.

\section{Methods}

\section{Sample population}

Data were collected in 2013-2014 as part of a crosssectional study of adults with type 2 diabetes. Six hundred and fifteen adults with type 2 diabetes, recruited from primary care clinics in the Southeast USA, completed a series of validated questionnaires intended to measure the impact of social determinants of health on individuals with diabetes. Eligibility to participate included age 18 years or older, diagnosis of type 2 diabetes noted in the medical record and ability to communicate in English. If, after interaction with the research coordinators, patients were determined to be cognitively impaired, they were considered ineligible. Participants were recruited through two methods: a letter of invitation sent to their home describing the study and inviting them to participate; and direct invitation by a research coordinator in the clinic waiting room. Prior to consent, all participants were provided a detailed explanation of the study and procedures were approved by the local institutional review board before initiation of enrolment. Following completion of the selfadministered survey, glycosylated $\mathrm{Hb}$ (HbA1c) levels were abstracted from the medical record.

\section{Measures}

Food insecurity

Food insecurity was measured using the US Household Food Security Survey Module: Six-Item Short Form scale developed by the National Center for Health Statistics ${ }^{(4,20)}$. This subset of the original eighteen-question survey reduces respondent burden and is used by several national health surveys, as well as the US Department of Agriculture's Economic Research Service, as a more parsimonious way to measure food insecurity ${ }^{(20)}$. The six-item scale was shown to identify food-insecure households with good specificity and sensitivity relative to the eighteen-item scale, particularly for studies focused on adult populations ${ }^{(20)}$. Questions ask about whether participants did not have enough money to buy more food in the past 12 months, if they could not afford to eat balanced meals, if they ever had to cut the size of their meals because there was not enough money or if they ever ate less than they felt they should because there was not enough food. Scoring increases for increased frequency of these experiences ${ }^{(20)}$. Raw scores of 0 or 1 indicate high or marginal food security, raw scores of 2-4 indicate low food security, and raw scores of 5 or 6 indicate very low food security ${ }^{(20)}$.

\section{Perceived stress}

The Perceived Stress Scale (PSS) is a brief four-item scale to assess the degree to which the respondent finds situations stressful $^{(21)}$. As the current study focused on psychosocial influences on food insecurity, the perception of stress, rather than a laboratory measure of stress (e.g. cortisol level), was chosen. Participants are asked about the frequency of feelings over the last month related to feeling unable to control important things, lack of confidence in ability to handle problems and difficulties piling up so high they were not able to overcome them ${ }^{(21)}$. Responses range from 0 ('never') to 4 ('very often'), with higher scores indicating more perceived stress ${ }^{(21)}$. The Cronbach's $\alpha$ value for the scale is reported as 0.69 , and scores are highly correlated with stress, depression and anxiety ${ }^{(22)}$.

\section{Social support}

Three items representing positive social interaction from the Medical Outcomes Study (MOS) Social Support Survey were used to measure social support ${ }^{(23)}$. The three-item positive social interaction portion of the MOS survey measures frequency with which the respondent has someone to have a good time with, someone to get together with for relaxation and someone to do something enjoyable with ${ }^{(23)}$. The Cronbach's $\alpha$ for the social interaction subscale was 0.94; it was shown to have good reliability $(0 \cdot 77)$, high correlation with other subscales (0.65 to 0.88$)$ and 1-year test-retest reliability exceeding the 0.50 standard $(0.72)^{(23)}$.

\section{Diabetes self-care}

Behavioural skills were assessed with the twelve-item Summary of Diabetes Self-Care Activities (SDSCA) scale, a brief validated self-report questionnaire of diabetes selfmanagement actions ${ }^{(24)}$. Questions assess frequency over 
the past $7 \mathrm{~d}$ respondents followed a healthy diet, ate fruits and limited fat in their diet, exercised, completed blood glucose testing and checked their feet. The average interitem correlations within scales are high, and correlations with other measures of diet and exercise support the validity of the SDSCA subscales ${ }^{(24)}$. Medication adherence was measured with the eight-item self-report Morisky Medication Adherence Scale (MMAS), with each item measuring a specific medication-taking behaviour ${ }^{(25)}$. The scale has high reliability $(\alpha=0.83)$, with higher scores indicating lower adherence ${ }^{(25)}$.

\section{Glycaemic control}

HbA1c provides an average glycaemic control over the past 3 months and is the clinical standard of care to determine diabetes control. The most recent HbA1c measure within the previous 6 months was abstracted from the medical record.

\section{Demographics}

Previously validated questions from the National Health Interview Survey ${ }^{(26)}$ were asked to collect age, gender, race/ethnicity, marital status, employment status, education level, household income, health insurance and duration of diabetes. In addition, the single-item self-rated health question used in the National Health Interview Survey was asked to collect health status.

\section{Statistical analysis}

Structural equation modelling (SEM) was used to investigate mechanisms through which food insecurity influences diabetes self-care behaviours and glycaemic control. SEM combines regression, path analysis and factor analysis, allowing estimation and modelling of closely related predictors while taking measurement error into account ${ }^{(27-29)}$. Cross-sectional designs analysed using SEM, however, do not provide evidence of causation ${ }^{(27)}$. Therefore, the results are interpreted within the context of data collection. By incorporating multiple independent and dependent variables in the same model, SEM allows simultaneous testing of direct and indirect effects ${ }^{(30)}$. After descriptive statistics were completed to ensure multivariate normal and linearly related variables, confirmatory factor analysis was used to test latent factors for food insecurity, perceived stress, social support and self-care. Alpha statistics and loading were used to test the goodness-of-fit for each factor using principal component factor analysis ${ }^{(31)}$.

First, descriptive statistics were run to provide demographic information (Table 1) and details on the scales used in the analysis (Table 2). Second, pairwise correlations were completed between measures included in the initial SEM model (Table 3). Finally, SEM was used to investigate the hypothesized model based on a priori specifications. The hypothesized model can be seen in Fig. 1, with the final model shown in Fig. 2. Direct, indirect and total effects were
Table 1 Sample demographics for adults with diabetes ( $n$ 615) included in the present study, Southeast USA, 2013-2014

\begin{tabular}{|c|c|c|c|}
\hline & Mean & & SD \\
\hline Age (years) & $61 \cdot 3$ & & $10 \cdot 9$ \\
\hline Diabetes duration (years) & $12 \cdot 3$ & & $9 \cdot 1$ \\
\hline Education (years of school) & 13.4 & & $2 \cdot 8$ \\
\hline \multirow{2}{*}{ Employment (h/week) } & 12.5 & & 19.0 \\
\hline & & $\%$ & \\
\hline \multicolumn{4}{|l|}{ Race } \\
\hline White & & 33.0 & \\
\hline Black & & 64.9 & \\
\hline Other & & $2 \cdot 1$ & \\
\hline \multicolumn{4}{|l|}{ Gender } \\
\hline Women & & 38.4 & \\
\hline Men & & $61 \cdot 6$ & \\
\hline \multicolumn{4}{|l|}{ Marital status } \\
\hline Never married & & $11 \cdot 2$ & \\
\hline Married & & $49 \cdot 7$ & \\
\hline Separated/divorced & & $28 \cdot 2$ & \\
\hline Widowed & & $10 \cdot 9$ & \\
\hline \multicolumn{4}{|l|}{ Annual income (\$US) } \\
\hline$<10000$ & & $20 \cdot 2$ & \\
\hline $10000-14999$ & & 11.3 & \\
\hline $15000-19999$ & & $10 \cdot 1$ & \\
\hline $20000-24999$ & & 10.4 & \\
\hline $25000-34999$ & & 14.7 & \\
\hline $35000-49999$ & & $13 \cdot 8$ & \\
\hline $50000-74999$ & & $10 \cdot 1$ & \\
\hline$\geq 75000$ & & 9.4 & \\
\hline \multicolumn{4}{|l|}{ Insurance } \\
\hline None & & $9 \cdot 3$ & \\
\hline Private & & $20 \cdot 2$ & \\
\hline Medicare & & 24.7 & \\
\hline Medicaid & & $10 \cdot 2$ & \\
\hline Veterans Affairs & & 23.9 & \\
\hline Other & & $11 \cdot 7$ & \\
\hline \multicolumn{4}{|l|}{ Health status } \\
\hline Excellent & & 1.3 & \\
\hline Very good & & $12 \cdot 0$ & \\
\hline Good & & $38 \cdot 2$ & \\
\hline Fair & & $38 \cdot 7$ & \\
\hline Poor & & 9.8 & \\
\hline
\end{tabular}

assessed in the final model (Table 4). Analyses were completed using the statistical software package Stata version 14 with standardized estimates and the 'mlmv' option, which retains variables rather than using listwise deletion for missing data. Standardized estimates can be interpreted as the change in SD of the outcome resulting from $1 \mathrm{SD}$ of the predictor and allow comparison between estimates. The fit of individual paths was determined by a significance of $P<0 \cdot 05$. The model fit was investigated using multiple fit statistics, as recommended by best practices for $\mathrm{SEM}^{(32)}$. As $\chi^{2}$ is sensitive to sample size, we used the root-meansquare error of approximation (RMSEA), comparative fit index (CFI) and Tucker fit index (TFI). (Hooper) RMSEA values lower than 0.05 , CFI values above 0.9 and TFI values above 0.9 indicate good $\mathrm{fit}^{(33)}$. A sample size of 615 provided the recommended 20:1 (subject to variable) ratio needed to maintain $80 \%$ power while estimating stable parameters and minimizing the possibility of oversaturating the model ${ }^{(28,32)}$. 
Table 2 Descriptive statistics for variables of interest included in the final model for adults ( $n 615)$ with type 2 diabetes, Southeast USA, 2013-2014

\begin{tabular}{lll}
\hline Factors & Mean & SD \\
\hline Food insecurity & & \\
Fl-1 & $0 \cdot 4$ & $0 \cdot 5$ \\
Fl-2 & $0 \cdot 3$ & $0 \cdot 5$ \\
FI-3 & $0 \cdot 2$ & $0 \cdot 4$ \\
Fl-4 & $0 \cdot 1$ & $0 \cdot 3$ \\
Fl-5 & $0 \cdot 2$ & $0 \cdot 4$ \\
FI-6 & $0 \cdot 1$ & $0 \cdot 3$ \\
Perceived stress & & \\
PSS-1 & $1 \cdot 2$ & $1 \cdot 1$ \\
PSS-2 & $1 \cdot 4$ & $1 \cdot 3$ \\
PSS-3 & $1 \cdot 5$ & $1 \cdot 1$ \\
PSS-4 & $1 \cdot 3$ & $1 \cdot 2$ \\
Social support & & \\
MOS-16 & $4 \cdot 0$ & $1 \cdot 2$ \\
MOS-17 & $3 \cdot 9$ & $1 \cdot 3$ \\
MOS-18 & $3 \cdot 9$ & $1 \cdot 3$ \\
Glycaemic control (HbA1c; \%) & $7 \cdot 9$ & $1 \cdot 8$ \\
Self-care & & \\
Medication adherence & $5 \cdot 9$ & $2 \cdot 0$ \\
General diet & $4 \cdot 7$ & $2 \cdot 0$ \\
Special diet & $4 \cdot 0$ & $1 \cdot 6$ \\
Exercise & $2 \cdot 6$ & $2 \cdot 2$ \\
Blood sugar testing & $4 \cdot 6$ & $2 \cdot 5$ \\
Foot care & $4 \cdot 3$ & $2 \cdot 5$ \\
\hline
\end{tabular}

FI, food insecurity; PSS, Perceived Stress Scale; MOS, Medical Outcomes Study Social Support Survey; $\mathrm{HbA1c}$, glycosylated $\mathrm{Hb}$.

Note: Numbers indicate the item in the scale (i.e. Fl-1 is the first item in the food insecurity scale).

\section{Results}

Sample demographics are reported in Table 1 . The mean age of participants was 61.3 (SD 10.9) years and mean duration of diabetes was 12.3 (SD 9.1) years. The sample consisted of $38.4 \%$ women and $64.9 \%$ non-Hispanic Blacks. Fifty-two per cent of the sample reported annual income below \$US 25 000. Regarding health status, 13.3\% reported excellent or very good health, 38.2 and $38.7 \%$ reported good and fair health, respectively, and $9.8 \%$ reported poor health.

Table 2 presents descriptive statistics for the variables of interest including food insecurity, perceived stress, social support, glycaemic control and self-care behaviours. Table 3 presents pairwise correlations between the measures included in these variables.

Figure 1 shows the hypothesized relationships tested, and Fig. 2 shows the final model. Table 4 presents the standardized direct, indirect and total effects for the relationship between food insecurity, self-care behaviours and glycaemic control from the final model $\left(\chi_{(158)}^{2}=301.97\right.$, $P<0.001, \quad R^{2}=0.98, \quad$ RMSEA $=0.038, \quad$ CFI $=0.977, \quad$ TFI $=$ 0.972). The final model showed that higher food insecurity was directly significantly related to increased stress $(r=0.14, \quad P<0.001)$ and increased HbA1c $(r=0.66$, $P=0.03)$. Higher perceived stress was significantly related to poorer self-care $(r=-0.54, P<0.001)$ and lower social support $(r=-0.41, P<0 \cdot 001)$. There was no significant direct association between food insecurity and self-care, or between perceived stress and glycaemic control.

\section{Discussion}

Using a sample of primary care patients with diabetes, we found that food insecurity has a direct relationship to glycaemic control outside the influence of self-care and that stress serves as a pathway through which food insecurity influences self-care behaviours. The indirect relationship on self-care suggests that efforts to address stress may help improve the ability of food-insecure individuals with diabetes to perform self-care behaviours. The direct effect on glycaemic control suggests that pathways independent of self-care behaviours may also be necessary to improve diabetes outcomes. Therefore, results from the present study suggest a multipronged approach is necessary to address food insecurity in individuals with diabetes, including both support in obtaining healthy food and support in coping with stress that can impact selfmanagement behaviours.

The findings of the present study provide important information regarding mechanisms to explain the relationship between food insecurity and health outcomes for individuals with diabetes. A better understanding of the factors that lead to poor outcomes can inform more targeted support interventions to address individuals with food insecurity ${ }^{(34)}$. Current intervention efforts have focused on decreasing the cost of fresh vegetables and improving the diet quality of food-insecure patients ${ }^{(9)}$. While programmes like the Supplemental Nutrition Assistance Program and emergency food banks can be effective at increasing food availability, some individuals may not be eligible and the food choices available may not be ideal for those with diabetes ${ }^{(5,10)}$. Pathways for interventions aimed at improving health outcomes may exist beyond improving the nutritional quality of food available to individuals, but currently the majority of interventions in food-insecure populations have focused on this pathway $^{(34)}$. The present study suggests that a focus on nutrition alone will not address the needs of individuals with diabetes and recommends additional pathways be targeted with future interventions.

Prior investigation into pathways explaining the relationship between food insecurity and health outcomes in patients with diabetes is limited. Our findings of stress as a pathway are supported by the results of Seligman et al., who found that difficulty following a diet and emotional distress met formal criteria as a mediator of the relationship $^{(12)}$. Emotional distress mediated $34 \%$ of the relationship between food insecurity and glycaemic control; whereas difficulty following a diet mediated only $20 \%{ }^{(12)}$. Maintaining a healthy diet while dealing with food insecurity may require considerably more time, planning and knowledge than patients have with the resources 
Table 3 Pairwise correlations for glycaemic control, self-care behaviours, food insecurity, perceived stress and social support variables included in the initial SEM model for adults ( $n 615$ ) with type diabetes, Southeast USA, 2013-2014

\begin{tabular}{|c|c|c|c|c|c|c|c|c|c|c|c|c|c|c|c|c|c|c|c|}
\hline & 1 & 2 & 3 & 4 & 5 & 6 & 7 & 8 & 9 & 10 & 11 & 12 & 13 & 14 & 15 & 16 & 17 & 18 & 19 \\
\hline 1. General diet & - & - & - & - & - & _- & - & - & - & - & - & _- & _- & - & _- & _- & - & - & _- \\
\hline 2. Specific diet & $0.36^{*}$ & - & - & - & - & - & - & - & - & - & - & - & - & - & - & - & - & - & - \\
\hline 3. Exercise & $0.29^{*}$ & $0.15^{*}$ & - & - & _- & _- & - & - & - & - & - & - & _- & - & - & - & - & - & - \\
\hline 4. BST & $0.21^{*}$ & $0.19^{*}$ & $0.11^{*}$ & _- & _- & _- & - & - & - & _- & _- & - & _- & - & - & - & _- & - & - \\
\hline 5. Foot care & $0.22^{*}$ & $0.22^{*}$ & $0.12^{*}$ & $0.28^{*}$ & - & - & - & - & - & - & - & - & - & - & - & - & - & - & - \\
\hline 6. Med. adh. & $0.28^{\star}$ & $0.26^{*}$ & $0.13^{\star}$ & $0.17^{*}$ & $0.23^{*}$ & - & - & - & - & - & - & - & - & - & - & - & - & - & - \\
\hline 7. $\mathrm{Fl}-1$ & $-0.17^{\star}$ & $-0.14^{*}$ & $-0.11^{*}$ & $-0.09^{\star}$ & -0.03 & $-0.19^{*}$ & - & - & - & - & - & - & _- & - & - & - & - & - & - \\
\hline 8. $\mathrm{FI}-2$ & $-0.19^{\star}$ & $-0.13^{*}$ & $-0.08^{\star}$ & -0.08 & 0.03 & $-0.20^{*}$ & $0.71^{*}$ & - & - & - & - & - & _- & - & - & - & - & - & - \\
\hline 9. $\mathrm{FI}-3$ & $-0.15^{\star}$ & $-0.10^{*}$ & $-0.09^{\star}$ & $-0.10^{\star}$ & -0.03 & $-0.20^{\star}$ & $0.52^{*}$ & $0.51^{*}$ & - & - & - & - & - & - & - & - & - & - & - \\
\hline 10. Fl-4 & $-0.12^{*}$ & $-0.10^{*}$ & $-0.09^{\star}$ & $-0.09^{\star}$ & -0.01 & $-0.15^{\star}$ & $0.46^{\star}$ & $0.42^{*}$ & $0.76^{*}$ & _- & _- & _- & _- & _- & _- & _- & _- & _- & _- \\
\hline 11. Fl-5 & $-0.17^{\star}$ & $-0.12^{*}$ & -0.07 & $-0.09^{\star}$ & -0.04 & $-0.24^{*}$ & $0.05^{*}$ & $0.55^{\star}$ & $0.76^{*}$ & $0.67^{\star}$ & _- & _- & _- & - & _- & - & _- & - & - \\
\hline 12. $\mathrm{FI}-6$ & $-0.16^{\star}$ & $-0.08^{*}$ & -0.03 & $-0.4^{*}$ & -0.07 & $-0.21^{*}$ & $0.42^{*}$ & $0.41^{*}$ & $0.63^{*}$ & $0.59^{\star}$ & $0.73^{*}$ & - & - & - & - & - & - & - & - \\
\hline 13. PSS-1 & $-0.18^{*}$ & $-0.23^{*}$ & $-0.18^{*}$ & $-0.13^{\star}$ & $-0.11^{*}$ & $-0.31^{\star}$ & $0.36^{\star}$ & $0.32^{*}$ & $0.30^{*}$ & $0.27^{\star}$ & $0.37^{\star}$ & $0.27^{\star}$ & _- & - & - & - & - & - & - \\
\hline 14. PSS-2 & -0.07 & -0.07 & -0.03 & -0.02 & 0.03 & $-0.13^{\star}$ & $0.18^{*}$ & $0.19^{\star}$ & $0.15^{\star}$ & $0.12^{*}$ & $0.15^{\star}$ & $0.16^{\star}$ & $0.11^{*}$ & - & - & - & - & - & - \\
\hline 15. PSS-3 & $-0.18^{\star}$ & $-0.11^{*}$ & -0.06 & -0.03 & -0.04 & $-0.19^{*}$ & $0.25^{*}$ & $0.24^{*}$ & $0.16^{\star}$ & $0.15^{\star}$ & $0.19^{\star}$ & $0.20^{*}$ & $0.27^{*}$ & $0.56^{\star}$ & - & - & - & - & - \\
\hline 16. PSS-4 & $-0.19^{\star}$ & $-0.21^{*}$ & $-0.11^{\star}$ & $-0.13^{\star}$ & $-0.10^{*}$ & $-0.29^{\star}$ & $0.37^{*}$ & $0.34^{*}$ & $0.28^{*}$ & $0.26^{*}$ & $0.31^{*}$ & $0.26^{\star}$ & $0.64^{*}$ & $0.11^{*}$ & $0.26^{*}$ & - & _- & - & - \\
\hline 17. MOS-16 & $0.19^{\star}$ & $0.15^{\star}$ & $0.13^{*}$ & 0.07 & $0.09^{*}$ & $0.17^{\star}$ & $-0.30^{*}$ & $-0.28^{\star}$ & $-0.19^{\star}$ & $-0.25^{\star}$ & $-0.27^{\star}$ & $-0.21^{\star}$ & $-0.37^{\star}$ & $-0.14^{\star}$ & $-0.29^{\star}$ & $-0.36^{\star}$ & - & - & - \\
\hline 18. MOS- 17 & $0.22^{*}$ & $0.18^{*}$ & $0.14^{*}$ & $0.08^{\star}$ & $0.12^{*}$ & $0.16^{*}$ & $-0.30^{*}$ & $-0.28^{\star}$ & $-0.21^{*}$ & $-0.25^{\star}$ & $-0.26^{\star}$ & $-0.21^{*}$ & $-0.42^{\star}$ & $-0.14^{*}$ & $-0.28^{\star}$ & $-0.37^{\star}$ & $0.91^{*}$ & - & - \\
\hline 19. MOS-18 & $0.22^{*}$ & $0.17^{*}$ & $0.15^{*}$ & $0.09^{\star}$ & $0.12^{*}$ & $0.18^{*}$ & $-0.29^{*}$ & $-0.25^{\star}$ & $-0.20^{*}$ & $-0.25^{\star}$ & $-0.25^{\star}$ & $-0.20^{\star}$ & $-0.41^{*}$ & $-0.14^{*}$ & $-0.30^{*}$ & $-0.38^{*}$ & $0.92^{*}$ & $0.94^{*}$ & - \\
\hline 20. $\mathrm{HbA} 1 \mathrm{c}$ & $-0.12^{\star}$ & -0.07 & $-0.10^{\star}$ & $0.10^{*}$ & 0.03 & $-0.20^{\star}$ & $0 \cdot 10^{*}$ & $0.11^{*}$ & $0.12^{*}$ & $0 \cdot 10^{\star}$ & $0 \cdot 17^{*}$ & $0.12^{\star}$ & $0.14^{*}$ & 0.04 & 0.001 & $0.15^{\star}$ & $-0.08^{\star}$ & -0.07 & -0.05 \\
\hline
\end{tabular}

SEM, structural equation modelling; BST, blood sugar testing; med. adh., medication adherence; FI, food insecurity; PSS, Perceived Stress Scale; MOS, Medical Outcomes Study Social Support Survey; HbA1c, glycosylated $\mathrm{Hb}$

Note: Numbers indicate the item in the scale (i.e. $\mathrm{Fl}-1$ is the first item in the food insecurity scale) 


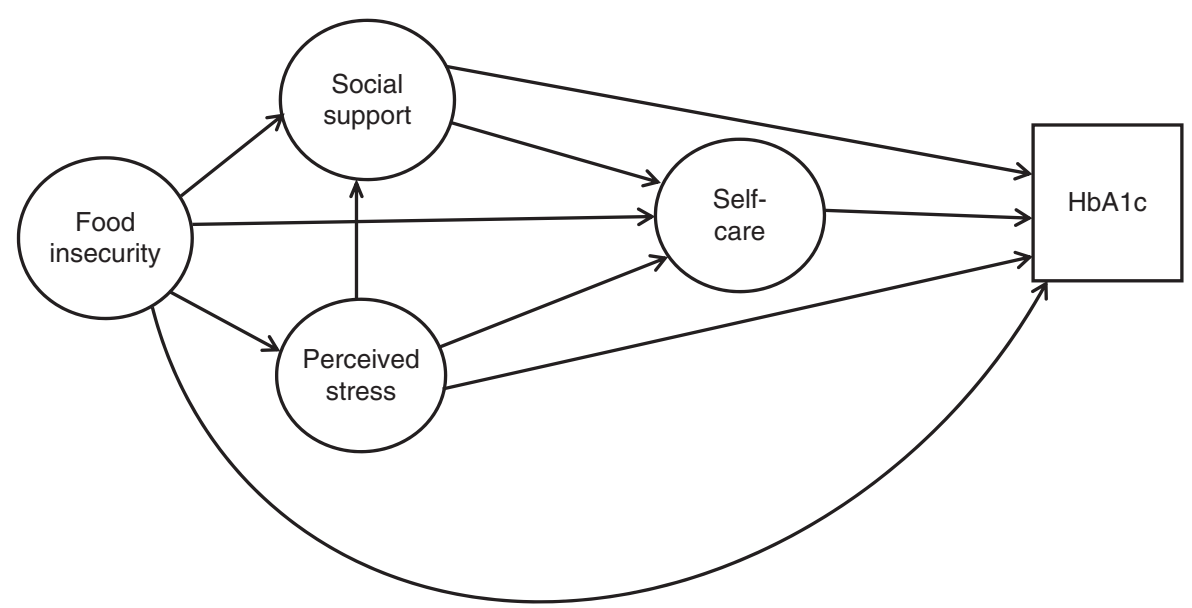

Fig. 1 Hypothesized model of the influence of food insecurity, perceived stress and social support on self-care and glycaemic control ( $\mathrm{HbA1c}$, glycosylated $\mathrm{Hb})$

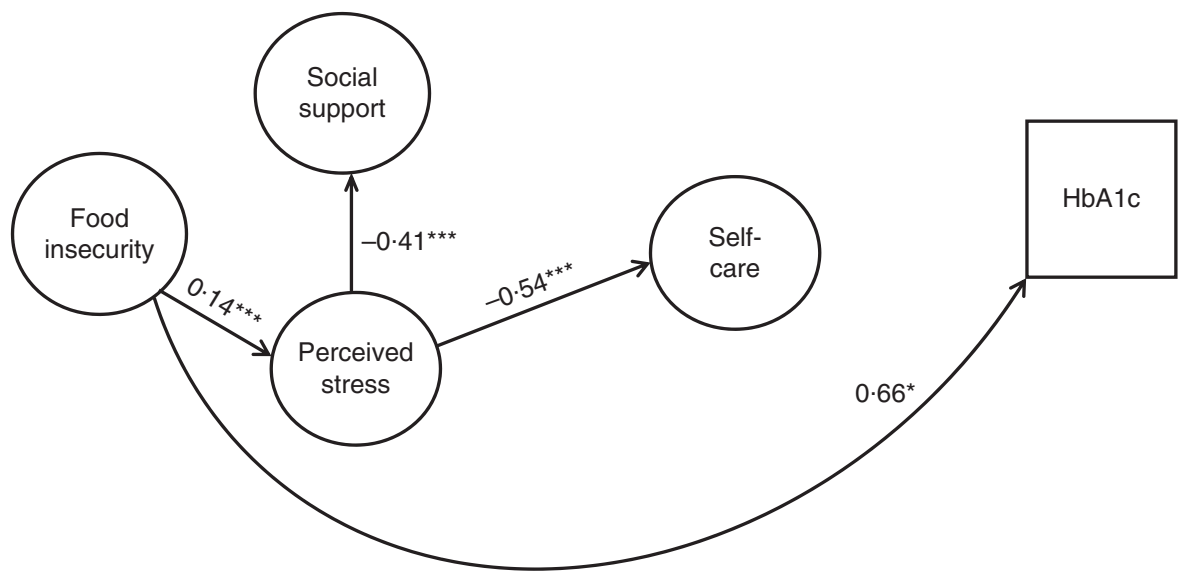

Fig. 2 Final model of the influence of food insecurity, perceived stress and social support on self-care and glycaemic control in adults ( $n$ 615) with type 2 diabetes, Southeast USA, 2013-2014. Note: Coefficients are standardized path coefficients; ${ }^{*} P<0.05$, ${ }^{\star \star \star} P<0.001$. Overall model fit: $\chi_{(158)}^{2}=301.97, P<0.001 ; R^{2}=0.98, \mathrm{RMSEA}=0.038, \mathrm{CFI}=0.977, \mathrm{TFI}=0.972$ (HbA1c, glycosylated $\mathrm{Hb}$; RMSEA, root-mean-square error of approximation; CFI, comparative fit index; TFI, Tucker fit index)

Table 4 Standardized direct, indirect and total effects for the relationship between food insecurity, perceived stress, self-care behaviours and glycaemic control in the final SEM model for adults $(n 615)$ with type 2 diabetes, Southeast USA, 2013-2014

\begin{tabular}{|c|c|c|c|}
\hline & Direct effects & Indirect effects & Total effects \\
\hline \multicolumn{4}{|l|}{ Self-care behaviours } \\
\hline Food insecurity & -0.36 & - & -0.36 \\
\hline Perceived stress & $-0.54^{\star \star \star}$ & -0.05 & $-0.59^{\star \star *}$ \\
\hline Social support & 0.11 & $0.25^{\star \star \star}$ & $0.36^{\star \star \star}$ \\
\hline \multicolumn{4}{|l|}{ Perceived stress } \\
\hline Social support & $-0.41^{\star \star *}$ & - & $-0.41^{\star \star \star}$ \\
\hline \multicolumn{4}{|l|}{ Food insecurity } \\
\hline Perceived stress & $0.14^{\star \star *}$ & - & $0 \cdot 14^{\star \star \star}$ \\
\hline Social support & -0.02 & $-0.06^{\star \star \star}$ & $-0.07^{\star \star \star}$ \\
\hline \multicolumn{4}{|l|}{ Glycaemic control } \\
\hline Self-care & -0.13 & - & -0.13 \\
\hline Food insecurity & $0.66^{\star}$ & 0.05 & $0.71^{\star}$ \\
\hline Perceived stress & 0.21 & $0.17^{\star}$ & $0.38^{\star \star}$ \\
\hline Social support & 0.08 & $-0 \cdot 18^{\star \star \star}$ & -0.10 \\
\hline
\end{tabular}

Note: Structural equation modelling (SEM) was used to investigate direct and indirect effects. Significant direct effects indicate direct associations between variables. For example, increased food insecurity is associated with poorer glycaemic control (i.e. higher glycosylated $\mathrm{Hb}$ ). Significant indirect effects indicate pathways through which variables influence outcomes. For example, increased food insecurity is associated with social support through perceived stress.

${ }^{\star} P<0.05,{ }^{\star \star} P<0.01,{ }^{\star \star \star} P<0.001$. 
currently provided ${ }^{(12)}$. This can include the information and skills necessary to support good self-care, as well as the social support necessary for long-term success. After completion of a diabetes self-management intervention, individuals who were food insecure showed a significant improvement in glycaemic control, whereas those who were food secure did not ${ }^{(8)}$. They also showed significant improvement in diabetes self-efficacy and increased fruit intake, suggesting that despite challenges faced obtaining food, the support of a self-management intervention was particularly important for food-insecure patients ${ }^{(8)}$. Social support was shown to serve as a buffer against increased prevalence of depressive symptoms in individuals with food insecurity ${ }^{(35)}$, a finding that supports our results of a relationship between social support and perceived stress. Individuals with diabetes reporting food insecurity noted that lack of funds limited socializing and made it difficult to eat and drink differently from friends ${ }^{(13)}$. And while community programmes, such as community kitchens and gardens, food distribution centres and meal programmes, allow interaction with others, they were not always able to attend $^{(13)}$.

\section{Limitations}

While the present study used sophisticated methodology to investigate pathways for the relationship between food insecurity and glycaemic control, there are some limitations. First, the analysis was based on cross-sectional data and therefore findings cannot speak to causality. While SEM is appropriate for non-experimental designs, its interpretation is linked to the method of data collection ${ }^{(27)}$. Second, the sample population was collected from primary care clinics in the Southeast USA and may not be representative of all areas within the USA. Although there is no indication that the impact of food insecurity on individuals with diabetes differs by region, additional studies should be conducted throughout the USA. In addition, this sample was $65 \%$ non-Hispanic Black, $62 \%$ male and had a mean age of 61 years. Generally, racial/ ethnic minorities, women and younger individuals report higher food insecurity ${ }^{(6,9)}$. Therefore, additional studies should test if the strength of these relationships is maintained across populations with different representation of demographic factors. Finally, while SEM is a powerful technique for investigating mechanisms, it validates models as hypothesized prior to the analysis and additional variables not included in the model will be important to explore in the future.

\section{Conclusion}

In conclusion, we found that food insecurity influences health outcomes in patients with diabetes both through a direct influence on glycaemic control and an indirect influence on self-care through perceived stress. Results suggest future interventions to address food insecurity in patients with diabetes should consider factors that impede their ability to perform self-care behaviours, including eating a healthy diet.

\section{Acknowledgements}

Financial support: This study was supported by the National Institute of Diabetes and Digestive and Kidney Diseases (Principal Investigator: L.E.E.; grant number K24DK093699). The study sponsor had no role in study design, collection, analysis or interpretation of data, or writing the report. Conflict of interest: The authors declare no conflict of interest. Authorship: L.E.E. obtained funding for the study. R.J.W. and L.E.E. acquired, analysed and interpreted the data. R.J.W., J.S.W. and L.E.E. designed the study, drafted the article and critically revised the manuscript for intellectual content. All authors approved the final manuscript. Ethics of human subject participation: This study was conducted according to the guidelines laid down in the Declaration of Helsinki and all procedures involving human patients were approved by the Institutional Review Board of the Medical University of South Carolina, Charleston, SC, USA. Written informed consent was obtained from all patients.

\section{References}

1. Centers for Disease Control and Prevention (2017) National Diabetes Statistics Report, 2017. Atlanta, GA: US Department of Health and Human Services.

2. Ali MK, Bullard KM, Saaddine JB et al. (2013) Achievement in goals in US diabetes care, 1999-2010. N Engl J Med 368, $287-288$

3. Gucciardi E, Vahabi M, Norris N et al. (2014) The intersection between food insecurity and diabetes: a review. Curr Nutr Rep 3, 324-332.

4. Bickel G, Nord M, Price C et al. (2000) Guide to Measuring Household Food Security, Revised 2000. Alexandria, VA: US Department of Agriculture, Food and Nutrition Service.

5. Berkowitz SA, Berkowitz TSZ, Meigs JB et al. (2017) Trends in food insecurity for adults with cardiometabolic disease in the United States: 2005-2012. PLoS One 12, e0179172.

6. Seligman HK, Bindman AB, Vittinghoff E et al. (2007) Food insecurity is associated with diabetes mellitus: results from the NHANES 1999-2002. J Gen Intern Med 22, $1018-1023$.

7. Seligman HK \& Schillinger D (2010) Hunger and socioeconomic disparities in chronic disease. New Eng J Med $363,6-9$.

8. Lyles CR, Wolf MS, Schillinger D et al. (2013) Food insecurity in relation to changes in hemoglobin A1c, selfefficacy, and fruit/vegetable intake during a diabetes educational intervention. Diabetes Care 36, 1448-1453.

9. Berkowitz SA, Seligman HK \& Choudhry NK (2014) Treat or eat: food insecurity, cost-related medication underuse, and unmet needs. Am J Med 127, 303-310.e3.

10. Essien UR, Shahid NN \& Berkowitz SA (2016) Food insecurity and diabetes in developed societies. Curr Diab Rep 16, 79. 
11. Seligman HK, Laraia BA \& Kushel MB (2010) Food insecurity is associated with chronic disease among low-income NHANES participants. J Nutr 140, 304-310.

12. Seligman HK, Jacobs EA, Lopez A et al. (2012) Food insecurity and glycemic control among low-income patients with type 2 diabetes. Diabetes Care 35, 233-238.

13. Chan J, DeMelo M, Gingras J et al. (2015) Challenges of diabetes self-management in adults affected by food insecurity in a large urban centre of Ontario, Canada. Int J Endocrinol 2015, 903468.

14. Smalls BL, Gregory CM, Zoller JS et al. (2015) Assessing the relationship between neighborhood factors and diabetes related health outcomes and self-care behaviors. BMC Health Serv Res 15, 445.

15. Heerman WJ, Wallston KA, Osborn CY et al. (2016) Food insecurity is associated with diabetes self-care behaviours and glycaemic control. Diabet Med 33, 844-850.

16. Silverman J, Krieger J, Kiefer M et al. (2015) The relationship between food insecurity and depression, diabetes distress and medication adherence. J Gen Intern Med 30, 1476-1480.

17. Montgomery J, Lu J, Ratliff S et al. (2017) Food insecurity and depression among adults with diabetes: results from the National Health and Nutrition Examination Survey (NHANES). Diabetes Educ 43, 260-271.

18. Gallo LC \& Matthews KA (2003) Understanding the association between socioeconomic status and physical health: do negative emotions play a role? Psychol Bull 129, 10-51.

19. Pearlin LI, Lieberman MA, Menaghan EG et al. (1981) The stress process. J Health Soc Behav 22, 337-356.

20. Blumberg SJ, Bialostosky K, Hamilton WL et al. (1999) The effectiveness of a short form of the household food security scale. Am J Public Health 89, 1231-1234.

21. Cohen S \& Williamson G (1988) Perceived stress in a probability sample of the United States. In The Social Psychology of Health, pp. 31-67 [S Spacapan and S Oskamp, editors]. Newbury Park, CA: SAGE Publications, Inc.

22. Andreou E, Alexopoulos EC, Lionis C et al. (2011) Perceived stress scale: reliability and validity study in Greece. Int $J$ Environ Res Public Health 8, 3287-3298.
23. Sherbourne CD \& Stewart AL (1991) The MOS social support survey. Soc Sci Med 32, 705-714.

24. Toobert DJ, Hampson SE \& Glasgow RE (2000) The summary of diabetes self-care activities measure: results from 7 studies and a revised scale. Diabetes Care 23, 943-950.

25. Morisky DE, Green LW \& Levine DM (1986) Concurrent and predictive validity of a self-reported measure of medication adherence. Med Care 24, 67-74.

26. National Center for Health Statistics (2004) Survey Questionnaire, National Health Interview Survey, 2002. Hyattsville, MD: NCHS.

27. Kline RB (2016) Principles and Practice of Structural Equation Modeling, 4th ed. New York: Guilford Press.

28. Schumacker RE \& Lomax RG (2010) A Beginner's Guide to Structural Equation Modeling, 3rd ed. New York: Taylor and Francis Group.

29. Hoyle R (2000) Confirmatory factor analysis. In Handbook of Applied Multivariate Statistics and Mathematical Modeling, pp. 465-497 [HEA Tinsley and SD Brown, editors]. San Diego, CA: Academic Press.

30. Sanchez BN, Budtz-Jorgensen E, Ryan LM et al. (2005) Structural equation models: a review with applications to environmental epidemiology. J Am Stat Assoc 100, $1443-1455$.

31. Byrne B (2005) Factor analytic models: viewing the structure of an assessment instrument from three perspectives. J Pers Assess 85, 17-32.

32. Schreiber JB (2008) Core reporting practices in structural equation modeling. Res Soc Admin Pharm 4, 83-97.

33. Hooper D, Caughlan J \& Mullen MR (2008) Structural equation modeling: guidelines for determining model fit. Electron J Bus Res Methods 6, 53-60.

34. Barnard LS, Wexler DJ, DeWalt D et al. (2015) Material need support interventions for diabetes prevention and control: a systematic review. Curr Diab Rep 15, 574.

35. Kollannoor-Samuel G, Vega-López S, Chhabra J et al. (2012) Food insecurity and low self-efficacy are associated with health care access barriers among Puerto-Ricans with type 2 diabetes. J Immigr Minor Health 14, 552-562. 